\title{
Potential immunological functions of salivary Hsp70 in mucosal and periodontal defense mechanisms
}

\author{
Tibor Károly Fábián ${ }^{1}$, Pál Fejérdy $^{1}$, Minh Tú Nguyen $^{2}$, Csaba Sóti $^{2}$ and Péter Csermely ${ }^{2}$ \\ ${ }^{1}$ Clinic of Prosthetic Dentistry, Faculty of Dentistry, Semmelweis University Budapest, Budapest, Hungary \\ ${ }^{2}$ Department of Medical Chemistry, Faculty of Medicine, Semmelweis University Budapest, Budapest, Hungary
}

Received: 2006.06.29, Accepted: 2006.12.29

\begin{abstract}
Molecular chaperones were considered to be intracellular, but there is increasing evidence demonstrating their cytoprotective and immune modulator properties outside the cell. The major extracellular chaperone (Hsp70) was also found in saliva, indicating a possible effect of Hsp70 on mucosal surfaces. Here we summarize the immune-modulatory role of the 70-kDa stress protein family, with special attention on the potential impact of salivary Hsp70 on oral defense mechanisms. There are three major facets of Hsp70-induced immune activation: 1) the appearance of Hsp70 on the surface of certain tumor cells or virally infected cells, leading to their phagocytosis and subsequent lysis; 2) the role of extracellular uncomplexed Hsp70 as a danger signal, leading to the secretion of proinflammatory cytokines from antigen-presenting cells and T lymphocytes and of nitric oxide from macrophages as well as to complement activation; 3) receptor-mediated uptake of peptide-loaded Hsp70 to antigen-presenting cells and cross-presentation of the Hsp70-peptide complex as an antigen to cytotoxic T cells and natural killer lymphocytes. The immune-activating effect of salivary Hsp70 may also be highly important in oral defense, especially in areas where molecular and cellular participants of the immune response appear on the surface of the oral cavity (i.e. several lesions of the mucosa and the periodontal tissues).
\end{abstract}

Key words: Hsp70, extracellular, saliva, immune, mucosal, periodontal.

Abbreviations: Hsp70 - 70-kDa heat shock protein, IL-4 - interleukin-4, NO - nitric oxide, LPS - lipopolysaccharide, TNF- $\alpha$ - tumor necrosis factor $\alpha$, NK cell - natural killer lymphocyte, PMN leukocytes - polimorphonuclear leukocytes, TLR - Toll-like receptor.

Corresponding author: Tibor Károly Fábián, Clinic of Prosthetic Dentistry, Faculty of Dentistry, Semmelweis University Budapest, Budapest, Hungary, e-mail: FAB@fok.usn.hu

\section{INTRODUCTION}

The highly interesting research field dedicated to the extracellular functions of the molecular chaperon Hsp70 will be shortly summarized below. For further details, please refer to recent reviews $[7,39,50,52,54$, $58,63,71,72,74]$. Molecular chaperones used to be considered intracellular, but in recent years chaperones (predominantly the $70-\mathrm{kDa}$ heat shock protein - Hsp70) were also found extracellularly in human blood sera [64, $66,88]$, and the presence of some other chaperones (cpn10 and cpn60) was also reported in pancreatic juice [83]. The presence of a key molecular chaperone (Hsp70) in human saliva was also demonstrated in our previous studies [26, 27], indicating a possible effect of Hsp70 not only in the extracellular compartment and blood, but on mucosal surfaces as well.
There is increasing evidence for functions of Hsp70 outside of the cell, such as cytoprotection [36, 37, 41] and modulation of cytokine release and immunity [39, $51,53,54,58,63,65,72,76,84]$. All these functions may be important in relation to salivary Hsp70.

The cytoprotective properties occur through cell surface association [11, 41], which may be followed by internalization in some cases [36]. Although cytoprotective properties very likely contribute to the maintenance of oral mucosal integrity, these properties are not connected with immunological functions, and are not discussed in this paper.

Although there are several types of molecules and cells with immunological functions in the saliva, the potential immune-activating effect of salivary Hsp70 may also be highly important for two reasons: 1) salivary Hsp70 may play a role in the prevention of bacterial 
infections and maintaining mucosal and periodontal health due to a continuous unspecific defensive alert. The intention of this function is very similar to that of other salivary defense proteins, such as secretory IgA, lysozyme, lactoferrin, lactoperoxidase, and salivary agglutinins [14]. 2) Since saliva covers all surfaces of the oral cavity, the immune functions of salivary Hsp70 may become more pronounced in areas where the molecular and cellular participants of the immune response appear on the surface. These conditions include several kinds of smaller or larger lesions of the mucosa and inflammations of the periodontal tissues (i.e. the inflamed inner surface of the periodontal sulcus).

Because of the above-listed functions of salivary Hsp70, in the present review we would like to summarize our knowledge on the $70-\mathrm{kDa}$ stress protein family with special attention on its immune-modulatory role. The potential impact of salivary Hsp70 on the oral defense mechanisms in physiological and pathological states will also be highlighted.

\section{MEMBERS OF THE HSP70 MOLECULAR CHAPERONE FAMILY}

Hsp70 is a collective abbreviation of several similar molecules of the $70-\mathrm{kDa}$ molecular chaperone family. Many chaperones are also called stress or Hsp due to their increased expression after stress, e.g. heat shock. The most important members of the Hsp70 family are the constitutive cytosolic Hsc70 (Hsp73), the inducible cytosolic Hsp70 (Hsp72), the Bip (Grp78) localized in the endoplasmic reticulum, the mHsp70 (Grp75, mortalin [24]) localized in the mitochondria, and the several bacterial homologues such as DnaK (in E. coli). By using ATP, and working in concert with other chaperones and co-chaperones, the members of the Hsp70-family take part in nearly all of the typical intracellular chaperone functions, including protein folding [21, 22, 30, 38], refolding of damaged proteins [68], inhibition of aggregation $[30,38]$, resolubilization of aggregated proteins [73], the transport of several proteins [30,38], and the control of several signal transduction pathways $[9,60]$, including the induction of senescence [24]. Furthermore, Hsp70 proteins are also involved in many processes outside the cell, including cytoprotection [36, 37, 41], cytokine-releasing effects, and the modulation of various immune functions [39, 51, 53, 54, 64, 65, 72, 76, 84].

Although it has not yet been investigated in detail, it is very likely that salivary chaperone Hsp70 is not a new member of the Hsp70 chaperone family, but rather a mixture of several known Hsp70-type stress proteins, including Hsp72 and Hsp73 [26, 27].

\section{THE ORIGIN OF SALIVARY CHAPERONE HSP70}

Salivary Hsp70 may originate from five main sources: 1) salivary glands, 2) mucosal cells, 3) the peri- odontal tissues as exudated serum proteins or as direct blood contamination, 4) mucosal lesions as exudated serum proteins or as direct blood contamination, or 5) bacteria (bacterial Hsp70-homologues only). Of these sources, only the salivary gland origin of $\mathrm{Hsp} 70$ has been studied up to now [26, 27]. In our first study, a strong secretory stimulation (taste and chewing together) was used. The secretory parameters of salivary Hsp 70 were independent of those of amylase (a known secretory protein of salivary gland acinar cells), as well as moderately independent of the secretory parameters of total salivary protein [26]. (Total salivary protein is a mixture of proteins secreted from the acinar cells or passively transported from the blood serum through the glandular tissue $[32,69]$.) In our second study, independence of the secretory parameters from amylase and total protein was found related to psychological stimulation as well [27]. Although salivary Hsp70 is present in the human parotid saliva collected with direct cannulation of the parotid duct (authors' unpublished data), the above results indicate that Hsp70 is not secreted due to a secretory exocytotic process of the acinar cells. The transport of Hsp70 may involve passive transport via the salivary glands from blood serum, similarly to other blood proteins [32, 69] (i.e. albumin, blood group antigens, etc.). A passive transport or a small-capacity active transport $[26,27]$ from the striated duct cells of human salivary glands is also possible, since a higher amount of Hsp70 was detected in these cells compared with others with immunocytochemical methods [82].

Previous data indicated that the Hsp70 chaperone family lacks a conventional signal peptide sequence that would allow them to be transported through cytosolic or plasma membranes [35]. Consequently, transport [37, 40] would require either increased cell membrane permeability [29] or a specific exocytotic pathway, as already was reported from a hepatosplanchnic source [28] and from the brain [45] following body exercise. A possible way of specific exocytotic transport via an alternative vesicular pathway not involving the endoplasmic reticulum-Golgi compartment was already reported [13]. This alternative transport of Hsp70 may occur either through lipid rafts or through exosomes [44]. Lipid rafts (also termed detergent-insoluble glycolipid fractions or detergent-resistant membranes) are specialized plasma membrane microdomains enriched in cholesterol and sphingolipids and which form a distinct, liquid-ordered phase in the lipid bilayer of membranes [18]. Exosomes are small (40-90 nm) membrane vesicles that are secreted by numerous cell types [20, 43]. The release of Hsp70 through exosomes is independent of the common secretory pathway, because brefeldin-A, an inhibitor of the classical protein transport, did not block Hsp70 release in human peripheral blood mononuclear cells [43]. Moreover, the exosomal release is independent of lipid raft-dependent pathways, since treatment with methyl- $\beta$-cyclodextrin, a raft-disrupting drug, had no effect on Hsp70 release [43].

If such specific active transport mechanisms (i.e. 
lipid rafts or exosomes) for the excretion of salivary Hsp70 also exist, a release could be quickly triggered by neuronal signals and/or by neuroendocrine hormones [31]. Consequently, the transport would not require passive diffusion (i.e. from the blood serum) or a release following an increase in cell membrane permeability or cell-death [31].

\section{IMMUNO-MODULATORY EFFECTS OF HSP70}

Three major facets of immune activation have been described for Hsp70 (and other stress proteins) [52]. The first of these involves the appearance of Hsp70 on the surface of certain tumor cells or virally infected cells, leading to phagocytosis and lysis of these cells [10, 55, $56,67,74,79]$. New findings indicate that surface expression of Hsp70 on tumor cells is accompanied by Hsp70-release involving lipid rafts and exosomes and leading to an activation of natural killer (NK) cells also in the environment $[3,6,33]$.

The second facet of immune system activation involves extracellular uncomplexed ("free") Hsp70 as an ancestral danger signal $[49,50]$ of cellular stress, death, or lysis. The immune activation here is very similar to that of bacterial lipopolysacharides (LPS) and the effect of LPS and extracellular Hsp70 seems to be additive [16]. Binding of Hsp70 to Hsp70-receptors on antigen-presenting cells (i.e. macrophages) [19, 53, 77] and on T lymphocytes [12] induces the secretion of proinflammatory cytokines. Extracellular Hsp70 also induces inducible nitric oxide (NO) synthase and $\mathrm{NO}$ release from macrophages [61]. Uncomplexed Hsp70 may also activate NK lymphocytes (NK cells) [51, 53]. Although other authors could not detect these effect with highly purified Hsp70 preparations, and expected an endotoxin contamination as a reason behind such effects [7, 84], new results confirmed the real effect of uncomplexed extracellular Hsp70 as a danger signal inducing the secretion of proinflammatory cytokines (tumor necrosis factor (TNF)- $\alpha$, interleukin (IL)-1 $\beta$, and IL-6) from monocytes and macrophages $[1,16]$. The proinflammatory effect of Hsp70 is very likely exerted on innate immune cells through the Toll/IL-1 receptor signal pathway $[2,80]$ and NF- $\kappa \mathrm{B}[2,5]$. Hsp70 uses both Tolllike receptors (TLRs) for bacteria such as TLR2 (for Gram-positive) and TLR4 (for Gram-negative) [2, 25] and also the receptor of the $\alpha_{2}$-macroglobulin on macrophages [4]. Another important danger signal function of uncomplexed $\mathrm{Hsp} 70$ is that $\mathrm{Hsp} 70$ also induces complement activation via an antibody-independent alternative pathway [65]. Thus, Hsp70 is able to activate both the major humoral and cellular immune responses.

The third facet of immune system activation involves complexes of extracellular Hsp70 and other peptides. Because of its chaperoning ability, uncomplexed Hsp70 binds other peptides, and as a complex induces receptor-mediated uptake into antigen-presenting cells (i.e. macrophages, dendritic cells) to cross-present this complex as an antigen (coupled with MHC-I or MHC-II molecules) to cytotoxic T cells and NK cells [8, 10, 51, 74, 75, 79]. Although bacterial Hsp70 associates mainly with bacterial antigens, human Hsp70 associates peptides such as self peptides, tumor peptides, or viral peptides because these are derived from proteins synthesized in human cells [75]. This means that the antigenpresenting function of Hsp70 is important not only against bacteria, but also as an initiator of immune defense against tumor cells and viral infections $[8,10$, 51, 71, 74, 77, 79].

Besides the above described immune-activating effects, Hsp70 exerts immune regulatory and antiinflammatory functions as well $[63,76,81]$. It was shown that low-affinity $\mathrm{T}$ cells are reactive against autologous heat shock proteins [57], which might lead to the generation of Th2 (IL-4- and IL-10-producing), Th3 (transforming growth factor- $\beta$-producing), or Tr1 (IL-10-producing) regulatory $\mathrm{T}$ cell responses (and release of these regulatory cytokines) $[63,76,81]$.

\section{THE POSSIBLE DEFENSE FUNCTIONS OF SALIVARY HSP70 IN HEALTHY SUBJECTS}

On a healthy mucosal surface, an unspecific effect of salivary Hsp 70 should be expected first. This function is based on the finding that the Hsp70 protein family (of both mammalian and bacterial origin) specifically recognizes sulfoglycolipids (surface proteins of mucosal cells) in vitro [11]. Consequently, bacterial surface Hsp70 functions very likely as an adhesin to these cell surface sulfoglycolipids [11]. Since salivary Hsp70 may occupy sulfoglycolipid binding sites, Hsp70 is able to prevent such surface binding [11], leading to the prevention (or decrease) of bacterial adhesion to mucosal surfaces. The cytoprotective ability of salivary Hsp70 may also defend the mucosal integrity against possible extracellular toxins [41] and may decrease the apoptotic and necrotic liability of the cells [36], also even in health conditions.

The presence of several immune-competent cells on the healthy oral mucosal surface should also be considered, since oral mucosa is extensively populated by antigen-presenting cells (i.e. Langerhans and dendritic cell [23]) and there is also a considerable flux of neutrophils through the gingival sulcus into saliva even in health. Regarding these, an important potential function of salivary Hsp70 could be the modulation of antigen sampling, since uncomplexed Hsp70 binds other peptides, and as a complex induces receptor-mediated uptake into antigen-presenting cells [8, 10, 51, 74, 75, 79].

The composition of the gingival crevicular fluid produced by the healthy periodontal tissues is very similar to a serum transudate containing immune and inflammatory mediator proteins, such as members of the complement system, immunoglobulins, cytokines, and also immune cells such as polimorphonuclear (PMN) leuko- 
cytes, and monocytes/macrophages. Since saliva is blended with gingival crevicular fluid in (and/or around) the periodontal sulcus/pocket, the immunological functions of salivary Hsp70 may be more active in this area compared with other mucosal surfaces. The role of the function of salivary Hsp70 in this case can be understood as that of a confluent stimulator of the immune surveillance, which may strengthen the effectiveness of early immune reaction. Especially the complement-activating potential of Hsp70 [65] may be very important, since complement activation is usually the first intensive periodontal defense reaction against pathogenic bacteria. This stimulating effect may be rather important, since none of the other unspecific salivary defense proteins (i.e. lysozyme, lactoferrin, lactoperoxidase, and salivary agglutinins) activate complement by direct means, and the main immunoglobulin of the saliva, secretory $\operatorname{IgA}$, also does not have such a property.

\section{THE POSSIBLE DEFENSE FUNCTIONS OF SALIVARY HSP70 IN MUCOSAL LESIONS AND PERIODONTAL INFLAMMATIONS}

In the case of mucosal lesions, the immune defense is activated and both immune mediator molecules and immune competent cells come in contact with saliva on the surface of the lesion, where inflammatory serum exudate containing a high amount of complement system, immunoglobulins, immune and inflammatory mediators, PMN leukocytes, and monocytes/macrophages are usually present. In the case of periodontal inflammation, the situation is very similar. An inflammatory exudate appears very quickly in the periodontal sulcus containing molecular constituents such as the complement system, immunoglobulins, immune and inflammatory mediators, and immune active cells such as PMN leukocytes and monocytes/macrophages.

The first defense barrier is usually complement activation, followed by the opsonization of the bacteria with antibodies and the appearance of a higher number of PMN leukocytes and monocytes, leading to phagocytosis and the degranulation and lysis of PMN cells with liberation of lysosomal enzymes. Another important expected mechanism is antibody-catalyzed ozone formation on the surface of neutrophil PMN cells [59, 87], leading to effective killing of bacteria (regardless of the source or antigen specificity of the antibody [87]).

As a next step of the inflammation, lymphocytes (T cells, B cells, NK cells) appear in the connective tissue, but only very few of these cells appear on the surface of the lesions (or in the gingival fluid in the case of periodontal inflammation). Consequently, the potential effects of salivary Hsp70 on lymphocytes such as NK cells $[51,53]$, cytotoxic T cells [7, 51, 75, 84], or regulatory T cells $[63,76,81]$ may play a less important role in the mucosal and periodontal defense mechanisms.

In advanced phases of these processes, a higher amount of Hsp70 will be present also from the inflam- matory exudate of the blood sera and from the lysed cells and lysed bacteria $[47,62,78]$. In these cases, the importance of salivary Hsp70 can be considered as a large reservoir of a continuous supply of damaged Hsp70 molecules.

This continuous supply with salivary Hsp70 will be rather needed, since the above immune mechanisms not only kill and eliminate bacteria (or viruses), but the liberated lysosomal enzymes and reactive oxygen and nitrogen species, including the highly oxidative ozone formation, also destroy immune molecules (i.e. antibodies) and the surrounding cells, leading to tissue damage. Hsp70 may play a crucial role in defending these important molecules and tissues under these conditions by increasing the resistance of the cells against extracellular toxins [41], and decreasing the apoptotic and necrotic liability of the cells [36], and also because of its protein repair character (refolding ability) [68], the prevention of protein aggregation $[30,38]$, and resolubilization of such aggregates [73].

\section{POSSIBLE ROLE OF SALIVARY HSP70 UNDER STRESS CONDITIONS}

Stress response is one of the most highly conserved adaptive response in nature. In unicellular organisms, the stress response confers tolerance to a variety of stresses, including hyperthermia, hyperoxia, hypoxia, and other perturbations, which alter many functions of the cell, including protein synthesis and several signal transduction pathways [52]. This tolerance phenomenon is also extremely important in multicellular organisms. Studies examining the effect of stressor exposure on Hsp70 responses were mostly focused on intracellular Hsp70 levels, and many kinds of physical and chemical stressors were tested. In contrast to the vast literature on intracellular Hsp70, very few studies have tested the effect of stress on extracellular Hsp70. In these instances, stressors such as surgical operations [25], intense physical exercises [15, 28, 85], and short-run psychological stress $[16,31]$ were shown to induce extracellular Hsp70. An extracellular elevation of another kind of chaperon (Hsp60) was also shown to be induced by long-term psychosocial stress [46]. In our previous study, the significant prompt (i.e. within a few minutes) elevation of salivary Hsp70 was also demonstrated following psychological treatment [27].

In the pioneering study by Campisi et al. [16], acute psychological stress of rats was studied and the psychoimmunological consequences related to elimination of injected bacteria were measured. The acute stressor induced significant increases in Hsp70 levels in the blood rather quickly (latest after $25 \mathrm{~min}$ ) and the level remained elevated after $2 \mathrm{~h}$. As a consequence of this treatment, the elimination of the injected bacteria was significantly more effective, the diameter of the inflammatory reaction induced by the injected bacteria was significantly reduced, and the NO production in the 
inflamed area was significantly elevated. The effect related to the diameter of the inflamed area was reproducible with the administration of extracellular Hsp70 in unstressed animals, also indicating the crucial role of Hsp70 in the phenomenon. The psycho-immunological changes were strongly dependent of the stressor: inescapable tail shock induced the above impressive changes, whereas restraining did not significantly alter any of the mentioned parameters [16].

Although the elevation of proinflammatory cytokines (TNF- $\alpha$, IL-1 $\beta$, and IL-6) induced by Hsp70 were measured in the Campisi et al. study [16] only in vitro, the expected in vivo mechanisms of stress-induced immunological changes may be explained as follows: a psychological stress exposure increases extracellular Hsp70, which acts as a danger signal leading to facilitation of NO and proinflammatory cytokine production. During the appearance of bacterial (or viral) injuries, these may result in improved bacterial killing (or elimination of viruses) with less enlarged inflamed area and quicker elimination of the invader bacteria (or virus).

Since the elevation of extracellular Hsp70 develops at least partly via the classical stress response of the hypothalamus-pituitary gland-adrenal gland axis and/or sympathetic activation (i.e. the removal of the adrenal gland decreases the elevation of extracellular Hsp70 significantly) [31], it seems reasonable that all stressors activating the classical stress response described by Cannon [17] and Selye [70] would lead to similar elevation of extracellular Hsp70 with similar immunological consequences.

Although the changes in salivary Hsp70 in stress conditions have not yet been studied in detail, given that salivary Hsp70 may also be changed in relation to psychological stressors [27] it is reasonable to assume that other stresses may also lead to an increase in salivary Hsp70.

The consequence of such changes related to the oral defense mechanisms can be an advantageously elevated immune surveillance, which may strengthen the effectiveness of early immune reactions as described above. However, chronic stress may lead to a continuous activation that may result in the "exhaustion of the reserve". This in turn would lead to a decreased response in the long run. A clinical consequence of such a possibility would be longer healing time of mucosal lesions and the unexpected appearance or rapid destruction of the periodontal tissues (i.e. narcotizing gingivitis).

Another possible consequence may be the "overstimulation" of the immune responses. Some data in the literature suggest that overexpression of Hsp70 may play a role in the atopic-type immune reactions [34], but there are no data on whether increased amounts of Hsp70 would or would not be released from the cells. Similarly, some data indicate that Hsp70 may play a role in the haptenation of peptides, leading to the induction of T cell immunity and sensitization [48], but it is not yet known whether this effect is extracellular or not. If extracellular (salivary) Hsp70 disposes these effects, the clinical consequence of an "overstimulation" may be mucosal hypersensitivity and allergic reaction. The small mucosal lesions induced by wearing dentures may facilitate these effects because of the appearance of several immune cells and immune molecules on the lesion's surface, leading to allergic-irritative mucosal symptoms induced by dentures. Further, an irritative or allergic reaction in the periodontal area (i.e. related to fixed dentures such as crowns and bridges) may occur even more frequently, since the composition of the gingival crevicular fluid continuously produced by the periodontal tissues is very similar to a serum transudate, and usually some immune cells, PMN leukocytes, and monocytes/macrophages are also present.

The possible role of the increased level of extracellular Hsp70 (including salivary Hsp70) in several autoimmune mechanisms should also be considered [58, $63,76]$ related to both mucosal and periodontal tissues. Although Hsp70 shows rather pronounced proinflammatory effects which may lead to such disorders $[63,76]$, administration of recombinant $\mathrm{Hsp} 70$ can attenuate experimental autoimmune diseases [42, 86]. These findings indicate that extracellular Hsp70 may take part not only in the release, but also in the control of the inflammatory conditions of such disorders $[63,76]$.

\section{CONCLUSIONS}

As a summary, it may be established that extracellular Hsp70 plays an important role in immune modulation. Extracellular Hsp70 is able to activate both the major humoral and cellular immune responses. The antigen-presenting function of extracellular Hsp70 is important not only against bacteria, but also as an initiator of immune defense against tumor cells and viral infections.

The immune-activating effect of salivary Hsp70 may also be highly important in the oral defense, especially in areas where the molecular and cellular participants of the immune response appear on the surface. However our knowledge related to salivary Hsp70 is still rather limited. Some important questions needing to be answered are: What is the main source of salivary Hsp70? How is it transported? What is the specific gene responsible for the synthesis of it? Is the amount of salivary Hsp70 sufficient to be protective? Does it have a real immune-modulatory function? Is salivary Hsp70 unique to humans? Besides summarizing the possible role of salivary Hsp70 in oral immune functions, another goal of the present review was to stimulate research activities in connection with these questions.

Acknowledgment: Work in the authors' laboratory was supported by research grants from the EU 6th Framework program (FP6-506850, FP6-518230), the Hungarian Science Foundation (OTKA-F47281), and the Hungarian National Research Initiative (1A/056/2004 and KKK-0015/3.0). C.S. is a Bolyai Research Scholar of the Hungarian Academy of Sciences. 


\section{REFERENCES}

1. Asea A., Kraeft S., Kurt-Jones E. A., Stevenson M. A., Chen L. B., Finberg R. W., Koo G. C.and Calderwood S. K. (2000): Hsp70 stimulates cytokine production through a CD14 dependent pathway, demonstrating its dual role as a chaperone and cytokine. Nat. Med., 6, 435-442.

2. Asea A., Rehli M., Kabingu E., Boch J. A., Bare O., Auron P. E., Stevenson M. A. and Calderwood S. K. (2002): Novel signal transduction pathway utilized by extracellular HSP70: role of toll-like receptor (TLR) 2 and TLR 4. J. Biol. Chem., 277, 15028-15034.

3. Barreto A., Gonzalez J. M., Kabingu E., Asea A. and Fiorentino S. (2003): Stress-induced release of HSC70 from human tumors. Cell. Immunol., 222, 97-104.

4. Basu S., Binder R. J., Ramalingam T. and Srivastava P. K. (2001): CD91 is a common receptor for heat shock proteins gp96, hsp90, hsp70, and calreticulin. Immunity, 14, 303-313.

5. Basu S., Binder R. J., Suto R., Anderson K. M. and Srivastava P. K. (2000): Necrotic but not apoptotic cell death releases heat shock proteins, which deliver a partial maturation signal to dendritic cells and activate the NFkappa B pathway. Int. Immunol., 12, 1539-1546.

6. Bausero M. A., Gastpar R., Multhoff G. and Asea A. (2005): Alternative mechanism by which IFN-gamma enhances tumor recognition: active release of heat shock protein 72. J. Immunol., 175, 2900-2912.

7. Bausinger H., Lipsker D. and Hanau D. (2002): Heatshock proteins as activators of the innate immune system. Trends Immunol., 23, 342-343.

8. Blachere N. E., Li Z., Chandawarkar R. Y., Suto R., Jaikaria N. S., Basu S., Udono H. and Srivastava P. K. (1997): Heat shock protein-peptide complexes, reconstituted in vitro, elicit peptide specific cytotoxic T-lymphocyte response and tumor immunity. J Exp. Med., 186, 1315-1322.

9. Bornfeldt K. E. (2000): Stressing Rac, Ras, and downstream heat shock protein 70. Circ. Res., 86, 1101-1106.

10. Botzler C., Kolb H. J., Issels R. D. and Multhoff G. (1996): Noncytotoxic alkyl-lysophospholipid treatment increases sensitivity of leukemic K562 cells to lysis by natural killer (NK) cells. Int. J. Cancer, 65, 633-638.

11. Boulanger J., Faulds D., Eddy E. M. and Lingwood C. A. (1995): Members of the $70 \mathrm{kDa}$ heat shock protein family specifically recognize sulfoglycolipids: role in gamete recognition and mycoplasma-related infertility. J. Cell. Physiol., 165, 7-17.

12. Breloer M., Fleischer B. and Bonin A. V. (1999): In vivo and in vitro activation of $\mathrm{T}$ cells after administration of Agnegative heat shock proteins. J. Immunol., 162, 3141-3147.

13. Broquet A. H., Thomas G., Masliah J., Trugnan G. and Bachelet M. (2003): Expression of the molecular chaperone Hsp70 in detergent-resistant microdomains correlates with its membrane delivery and release. J. Biol. Chem., 278, 21601-21606.

14. Buddecke E. (1981): Biochemische Grundlagen der Zahnmedizin. de Druyter, Berlin-New York, 91-102.

15. Campisi J. and Fleshner M. (2003): The role of extracellular Hsp72 in acute stress-induced potentiation of innate immunity in physically active rats. J. Appl. Physiol., 94, 43-52.

16. Campisi J., Leem T. H. and Fleshner M. (2003): Stressinduced extracellular Hsp72 is a functionally significant danger signal to the immune system. Cell Stress Chaperones, 8, 272-286.

17. Cannon W. B. (1939): The Wisdom of the Body. Norton, New York.

18. Chen S., Bawa D., Besshoh S., Gurd J. W. and Brown I. R. (2005): Association of heat shock proteins and neuronal membrane components with lipid rafts from the rat brain. J. Neurosci. Res., 81, 522-529.

19. Chen W., Syldath U., Bellmann K., Burkart V. and Kolb H. (1999): Human $60 \mathrm{kDa}$ heat-shock protein: a danger signal to the innate immune system. J. Immunol., 162, 3212-3219.

20. Clayton A., Turkes A., Navabi H., Mason M. D. and Tabi Z. (2005): Induction of heat shock proteins in B-cell exosomes. J. Cell Sci., 118, 3631-3638.

21. Csermely P. (1997): Proteins, RNA-s and chaperones in enzyme evolution: a folding perspective. Trends Biochem. Sci., 22, 147-149.

22. Csermely P. (1999): Chaperone-percolator model: a possible molecular mechanism of Anfinsen-cage-type chaperones. BioEssay, 21, 959-965.

23. Cutler C. W. and Jotwani R. (2006): Dendritic cells at the oral mucosal interface. J. Dent. Res., 85, 678-689.

24. Deocaris C. C., Kaul S. C. and Wadhwa R. (2006): On the brotherhood of the mitochondrial chaperones mortalin and heat shock protein 60. Cell Stress Chaperones, 11, 116-128.

25. Dybdahl B., Wahba A., Lien E., Flo T. H., Waage A., Qureshi N., Sellevold O.F., Espevik T. and Sundan A. (2002): Inflammatory response after open heart surgery: release of heat-shock protein 70 and signaling through Toll-like receptor-4. Circulation, 105, 685-690.

26. Fábián T. K., Gáspár J., Fejérdy L., Kaán B., Bálint M., Csermely P. and Fejérdy P. (2003): HSP-70 is present in human saliva. Med. Sci. Monit., 9, 62-65.

27. Fábián T. K., Tóth Zs., Fejérdy L., Kaán B., Csermely P. and Fejérdy P. (2004): Photo-acoustic stimulation increases the amount of $70 \mathrm{kDa}$ heat shock protein (Hsp70) in human whole saliva. A pilot study. Int. J. Psychophysiol., 52, 211-216.

28. Febbraio M. A., Ott P., Nielsen H. B., Steensberg A., Keller C., Krustrup P., Secher N. H. and Pedersen B. K. (2002): Exercise induces hepatosplanchnic release of heat shock protein 72 in humans. J. Physiol., 544, 957-962.

29. Febbrario M. A., Steensberg A., Walsh R., Koukoulas I., Hall G., Saltin B. and Klarlund O. B. (2002): Reduced muscle glycogen availability is associated with elevated HSP72 in contracting human skeletal muscle. J. Physiol., 538, 911-917.

30. Fink A. (1999): Chaperone mediated protein folding. Physiol. Rev., 79, 425-449.

31. Fleshner M., Campisi J., Amiri L. and Diamond D. M. (2004): Cat exposure induces both intra- and extracellular Hsp72: the role of adrenal hormones. Psychoneuroendocrinology, 29, 1142-1152.

32. Garret J. R. (1981): Permeability of salivary glands to macromolecules. In Zelles T (ed.): Advances in Physiological Sciences. Pergamon Press - Akadémiai Kiadó, Budapest, 28, 109-118.

33. Gastpar R., Gehrmann M., Bausero M. A., Asea A., Gross C., Schroeder J. A. and Multhoff G. (2005): Heat shock protein 70 surface-positive tumor exosomes stimulate migratory and cytolytic activity of natural killer cells. Cancer Res., 65, 5238-5247.

34. Ghoreishi M., Yokozeki H., Hua W. M. and Nishioka K. 
(2000): Expression of $27 \mathrm{KD}, 65 \mathrm{KD}$ and 72/73 KD heat shock protein in atopic dermatitis: comparison with those in normal skin and contact dermatitis. J. Dermatol., 27, 370-379.

35. Gunter E. and Walter L. (1994): Genetic aspects of the Hsp70 multigene family in vertebrates. Experientia, 50, 987-1001.

36. Guzhova I. V., Arnholdt A. C., Darieva Z. A., Kinev A. V., Lasunskaia E. B., Nilsson K., Bozhkov V. M., Voronin A. P. and Margulis B. A. (1998): Effects of exogenous stress protein 70 on the functional properties of human promonocytes through binding to cell surface and internalization. Cell Stress Chaperones, 3, 67-77.

37. Guzhova I., Kislyakova K., Moskaliova O., Fridlanskaya I., Tytell M, Cheetham M. and Margulis B. (2001): In vitro studies show that, Hsp70 can be released by glia and that exogenous Hsp70 can enhance neuronal stress tolerance. Brain Res., 914, 66-73.

38. Hartl U. (1996): Molecular chaperones in cellular protein folding. Nature, 381, 571-580.

39. Henderson B., Nair S. P. and Coates A. R. (1996): Molecular chaperones and research. Inflamm. Res., 45, 155-158.

40. Hightower L. E. and Guidon P. T. Jr. (1989): Selective release from cultured mammalian cells of heat-shock (stress) proteins that resemble glia-axon transfer proteins. J. Cell. Physiol., 138, 257-266.

41. Johnson A. D. and Tytell M. (1993): Exogenous HSP70 becomes cell associated, but not internalized by stressed arterial smooth muscle cells. In Vitro Cell. Dev. Biol. Anim., 29, 807-812.

42. Kingston A. E., Hicks C. A., Colston M. J. and Billingham M. E. (1996): A $71 \mathrm{kDa}$ heat shock protein (hsp) from Mycobacterium tuberculosis has modulatory effects on experimental rat arthritis. Clin. Exp. Immunol., 103, 77-82.

43. Lancaster G. I. and Febbraio M. A. (2005): Exosomedependent trafficking of HSP70. J. Biol. Chem., 280, 23349-23355.

44. Lancaster G. I. and Febbraio M. A. (2005): Mechanisms of stress-induced cellular HSP72 release: implications for exercise-induced increases in extracellular HSP72. Exerc. Immunol. Rev., 11, 46-52.

45. Lancaster G. I., Moller K., Nielsen B., Secher N. H., Febbraio M. A. and Nybo L. (2004): Exercise induces the release of heat shock protein 72 from the human brain in vivo. Cell Stress Chaperon, 9, 276-280.

46. Lewthwaite J., Owen N., Coates A., Henderson H. and Steptoe A. (2002): Circulating human heat shock protein 60 in the plasma of British civil servants. Ciculation, 106, 196-201.

47. Lopatin D. E., Shelburne C. E., Van Poperin N., Kowalski C. J. and Bagramian R. A. (1999): Humoral immunity to stress proteins and periodontal disease. J. Periodontol., 70, 1185-1193.

48. Martin A. M., Nolan D., Gaudieri S., Almelda C. A., Nolan R., James I., Carvahlo F., Phillips E., Christiansen F. T., Purcell A. W., McCluskey J. and Mallal S. (2004): Predisposition to abacavir hypersensitivity conferred by HLA-B*5701 and a haplotypic Hsp70-hom variant. Proc. Natl. Acad. Sci. USA, 101, 4180-4185.

49. Matzinger P. (1994): Tolerance, danger, and the extended family. Annu. Rev. Immunol., 12, 991-1045.

50. Matzinger P. (2002): The danger model: a renewed sense of self. Science, 296, 301-305.

51. Milani V., Noessner E., Ghose S., Kuppner M., Ahrens B.,
Scharner A. Gastpar R. and Issels R. D. (2002): Heat shock protein 70: role in antigen presentation and immune stimulation. Int. J. Hyperthermia, 18, 563-575.

52. Moseley P. (2000): Stress proteins and the immune response. Immunopharmacology, 48, 299-302.

53. Multhoff G. (2002): Activation of natural killer cells by heat shock protein 70. Int. J. Hyperthermia, 18, 576-585.

54. Multhoff G. and Botzler C. (1998): Heat-shock proteins and the immune response. Ann. N.Y. Acad. Sci., 851, 86-93.

55. Multhoff G., Botzler C., Jennen L., Schmidt J., Ellwart J. and Issels R. (1997): Heat shock protein 72 on tumor cells: a recognition structure for natural killer cells. J Immunol., 158, 4341-4350.

56. Multhoff G., Botzler C., Wiesnet M., Eissner G. and Issels R. (1995): CD3- large granular lymphoctes recognize a heat-inducible immunogenic determinant associated with the $72 \mathrm{kD}$ heat shock protein on human sarcoma cells. Blood, 86, 1374-1382.

57. Munk M. E., Schoel B., Modrow S., Karr R. W., Young R. A. and Kaufmann S. H. (1989): T lymphocytes from healthy individuals with specificity to self-epitopes shared by the mycobacterial and human 65-kilodalton heat shock protein. J. Immunol., 143, 2844-2849.

58. Nardai G., Végh M.E., Prohászka Z. and Csermely P. (2006): Chaperone-related immune dysfunction: an emergent property of distorted chaperone networks. Trends Immunol., 27, 74-79.

59. Nathan C. (2002): Catalytic antibody bridges innate and adaptive immunity. Science, 298, 2143-2144.

60. Nollen E. A. and Morimoto R. (2002): Chaperoning signaling pathways: molecular chaperones as stress-sensing "heat-shock" proteins. J. Cell Sci., 115, 2809-2816.

61. Panjwani N. N., Popova L. and Srivastava P. K. (2002): Heat shock proteins gp96 and hsp70 activate the release of nitric oxide by APCs. J. Immunol., 168, 2997-3003.

62. Petit M. D., Wassenaar A., van der Velden U., van Eden W. and Loos B. G. (1999): Depressed responsiveness of peripheral blood mononuclear cells to heat-shock proteins in periodontitis patients. J. Dent. Res., 78, 1393-1400.

63. Pockley A. G. (2003): Heat shock proteins as regulators of the immune response. Lancet, 362, 469-476.

64. Pockley A. G., Shepherd J. and Corton J. M. (1998): Detection of heat shock protein 70 (Hsp70) and antyHsp70 antibodies in the serum of normal individuals. Immunol. Investig., 27, 367-377.

65. Prohászka Z., Sing M., Nagy K., Kiss E., Lakos G., Duba J. and Füst G.: (2002): Heat shock protein 70 is a potent activator of the human complement system. Cell Stress Chaperones, 7, 17-22.

66. Rea I. M., McNerlan S. and Pockley A. G. (2001): Serum heat shock protein and anti-heat shock protein antibody levels in aging. Exp. Gerontol., 36, 341-352.

67. Rogias J., Wallen E. S., Loening S. A. and Moseley P. L. (1998): Heat shock proteins (Hsp72) surface expression enhances the lysis of a human renal cell carcinoma by IL-2 stimulated NK cells. Adv. Exp. Med. Biol., 451, 225-229.

68. Schröder H., Langer T., Hartl F. U. and Bukau B. (1999): DnaK, DnaJ and GrpE form a cellular chaperone machinery capable of repairing heat-induced protein damage. EMBO J., 12, 4137-4144.

69. Schwartz S. S., Zhu W. X. and Sreebny L. M. (1995): Sodium dodecyl sulphate-polyacrylamide gel electrophoresis of human whole saliva. Arch. Oral Biol., 40, 949-958.

70. Selye H. (1955): Stress and disease. Science, 122, 625-631. 
71. Sõti C. and Csermely P. (1998): Molecular chaperones in the etiology and therapy of cancer. Pathol. Oncol. Res., 4, 316-321.

72. Srivastava P. K. (2002): Heat shock proteins in innate and adaptive immunity. Nat. Rev. Immunol., 2, 185-194.

73. Stevens J. L., Liu H., Halleck M., Bowes R. C. III, Chen Q. M. and van de Water B. (2000): Linking gene expression to mechanism of toxicity. Toxicol. Lett., 112-113, 479-486.

74. Suto R. and Srivastava P. K. (1995): A mechanism for the specific immunogenicity of heat shock protein-chaperoned peptides. Science, 269, 1585-1588.

75. Tobian A. A., Canaday D. H. and Harding C. V. (2004): Bacterial heat shock proteins enhance class II MHC antigen processing and presentation of chaperoned peptides to CD4 ${ }^{+}$T cells. J. Immunol., 173, 5130-5137.

76. Todryk S. M., Gough M. J.and Pockley G. (2003): Facet of heat shock protein 70 show immunotherapeutic potential. Immunology, 110, 1-9.

77. Todryk S., Melcher A., Hardwick N., Linardakis E., Bateman A., Colombo M., Stoppacciaro A. and Vile R. (1999): Heat shock protein 70 induced during tumor cell killing induces Th1 cytokines and targets immature dendritic cell precursors to enhance antigen uptake. J. Immunol., 163, 1398-1408.

78. Tomohiro A., Kato T., Ishihara K., Ogiuchi H. and Okuda K. (1995): Heat shock proteins in the human periodontal disease process. Microbiol. Immunol., 39, 321-327.

79. Udono H. and Srivastava P. K. (1993): Heat shock protein 70-associated peptides elicit specific cancer immunity. J. Exp. Med., 178, 1391-1396.

80. Vabulas R. M., Ahmad-Nejad P., Ghose S., Kirschning C. J., Issels R. D. and Wagner H. (2002): HSP70 as endogenous stimulus of the Toll/interleukin-1 receptor signal pathway. J. Biol. Chem., 277, 15107-15112.

81. van Eden W., van der Zee R., Paul A. G., Prakken B. J., Wendling U., Anderton S. M. and Wauben M. H. (1998):
Do heat shock proteins control the balance of T-cell regulation in inflammatory diseases? Immunol. Today, 19, 303-307.

82. Vanmuylder N., Evrard L., Daelemans P. and Dourov N. (2000): Chaperones in the parotid gland: localization of heat shock proteins in human adult salivary glands. Cell Tissues Organs, 167, 199-205.

83. Velez-Granell C. S., Arias A. E., Torres-Ruiz J. A. and Bendayan M. (1994): Molecular chaperones in pancreatic tissue: the presence of cpn10, cpn60, and Hsp70 in distinct compartments along the secretoric pathway of the acinar cells. J. Cell Sci., 107, 539-549.

84. Wallin R. P., Lundquist A., More S. H., von Bonin A., Kiessling R. and Ljunggren H. G. (2002): Heat-shock proteins as activators of the innate immune system. Trends Immunol., 23, 130-135.

85. Walsh R. C., Koukoulas I., Garnham A., Moseley P. L., Hagreaves M. and Febbraio M. A. (2001): Exercise increases serum Hsp72 in humans. Cell Stress Chaperones, 6, 386-393.

86. Wendling U., Paul L., van der Zee R., Prakken B., Singh M. and van Eden W. (2000): A conserved mycobacterial heat shock protein (hsp) 70 sequence prevents adjuvant arthritis upon nasal administration and induces IL-10-producing $\mathrm{T}$ cells that cross-react with the mammalian selfhsp70 homologue. J. Immunol., 164, 2711-2717.

87. Wentworth P., McDunn J. E., Wentworth A. D., Takeuchi C., Nieva J., Jones T., Bautista C., Ruedi J. M., Gutierrez A., Janda K. D., Babior B. M., Eschenmoser A. and Lerner R. A. (2002): Evidence for antibody-catalyzed ozone formation in bacterial killing and inflammation. Science, 298, 2195-2199.

88. Wright B. H., Corton J. M., El-Nahas A. M., Wood R. F. and Pockley A. G. (2000): Elevated levels of circulating heat shock protein (Hsp70) in peripheral and renal vascular disease. Heart Vessels, 15, 18-22. 